\title{
Prevalence of heart failure in Australia: a systematic review
}

\author{
Berhe W. Sahle ${ }^{1,2}$, Alice J. Owen ${ }^{1}$, Mutsa P. Mutowo ${ }^{3}$, Henry Krum ${ }^{1}$ and Christopher M. Reid ${ }^{1,4^{*}}$
}

\begin{abstract}
Background: In the absence of a systematic collection of data pertaining to heart failure, summarizing the data available from individual studies provides an opportunity to estimate the burden of heart failure. The present study systematically reviewed the literature to estimate the incidence and prevalence rates of heart failure in Australia.

Methods: Studies reporting on prevalence or incidence of heart failure published between 1990 and 2015 were identified through a systematic search of Embase, PubMed, Ovid Medline, MeSH, Scopus and websites of the Australian Institute of Health, and Welfare and Australian Bureau of Statistics.

Results: The search yielded a total of 4978 records, of which thirteen met the inclusion criteria. There were no studies reporting on the incidence of heart failure. The prevalence of heart failure in the Australian population ranged between $1.0 \%$ and $2.0 \%$, with a significant proportion of cases being previously undiagnosed. The burden of heart failure was higher among Indigenous than non-Indigenous Australians (age-standardized prevalence rate ratio of 1.7). Heart failure was prevalent in women than men, and in rural and remote regions than in the metropolitan and capital territories.

Conclusion: This systematic review highlights the limited available data on the epidemiology of heart failure in Australia. Population level studies, using standardized approaches, are needed in order to precisely describe the burden of HF in the population.
\end{abstract}

Keywords: Heart failure, Incidence, Prevalence, Indigenous, Australia

\section{Background}

Heart failure (HF) causes a significant burden for patients and healthcare systems in developed countries [1, 2]. Approximately $50-75 \%$ of patients with HF die within five years of diagnosis [3, 4]. Evidence shows that HF accounts for $1-3 \%$ of overall healthcare spending, mainly due to repeated hospital admissions and prolonged inpatient length of stay [1]. In developed countries, prevalence of HF ranges from $1-3 \%$, rising to $10 \%$ or more in those aged 75 years or older $[1,2]$, while estimates in developing countries are not routinely reported.

The relationship between obesity, hypertension, smoking and cholesterol with cardiovascular morbidity is undisputed. Australia has made significant attempts to address risk factors contributing to the onset of chronic diseases

\footnotetext{
* Correspondence: chris.reid@monash.edu

${ }^{1}$ Centre of Cardiovascular Research and Education in Therapeutics,

Department of Epidemiology and Preventive Medicine, Monash University,

99 Commercial Road, Melbourne, Vic 3004, Australia

${ }^{4}$ School of Public Health, Curtin University, Perth, Australia

Full list of author information is available at the end of the article
}

[5]. Public health policy on tobacco control, improvements in surgical treatment and the widespread use of lipid and blood pressure-lowering drugs have resulted in a significant decline in the burden of major cardiovascular diseases [5-8]. Despite these improvements, the burden of diabetes and obesity in the population has steadily increased over time [7].

Data on the incidence of HF is not reported in the Australian Institute of Health and Welfare (AIHW) periodic statistics [9], while the Australian National Health Surveys (NHS) report prevalence rates based on self-report [10]. However, self-reported data may underestimate the true burden of HF because the early stages of HF may be only mildly symptomatic; therefore many people may be unaware that they have the condition [7]. Similarly, estimation based on mortality data may under-report the actual burden of HF, as the international classification of diseases (ICD) recommends coding underlying causes of death such as ischemic heart diseases rather than HF, which is often the 
terminal illness of other cardiovascular diseases [10, 11]. Variation in the definition of HF and process of estimation therefore limit the validity and utility of data from these sources $[9,10]$.

Despite the morbidity and economic burden to the community and poor patient outcomes, there is a deficiency in the systematic collection of data pertaining the incidence and prevalence of HF. Therefore, summarizing the data available from individual studies provides an opportunity to estimate the burden of HF. The present study systematically reviewed the literature to estimate the incidence and prevalence rates of heart failure in Australia.

\section{Methods}

Literature search

The process of the review was designed and undertaken according to the Preferred Reporting Items for Systematic Reviews and Meta-Analyses (Additional file 1) guidelines [12]. We searched Embase, PubMed, Ovid Medline, MeSH, and Scopus for articles published under subject terms: heart failure, cardiac failure, congestive heart failure, chronic heart failure, left ventricular dysfunction, systolic heart failure, diastolic heart failure combined with epidemiology, incidence, prevalence, burden and morbidity. The search was limited to articles published in the Australian population in English, between September 1990 and 20 July 2015 (Additional file 2: Table S1). Relevant studies on the prevalence and incidence of HF in Australia were included. We further searched the AIHW and Australian Bureau of Statistics (ABS) websites to identify relevant datasets and reports.

\section{Study selection}

Figure 1 summarises the selection process for the studies. Publications retrieved from all databases were organized in Endnote and duplicate publications were removed (by BW). Two reviewers (BWS and MPM) independently reviewed abstracts and full text citations to screen
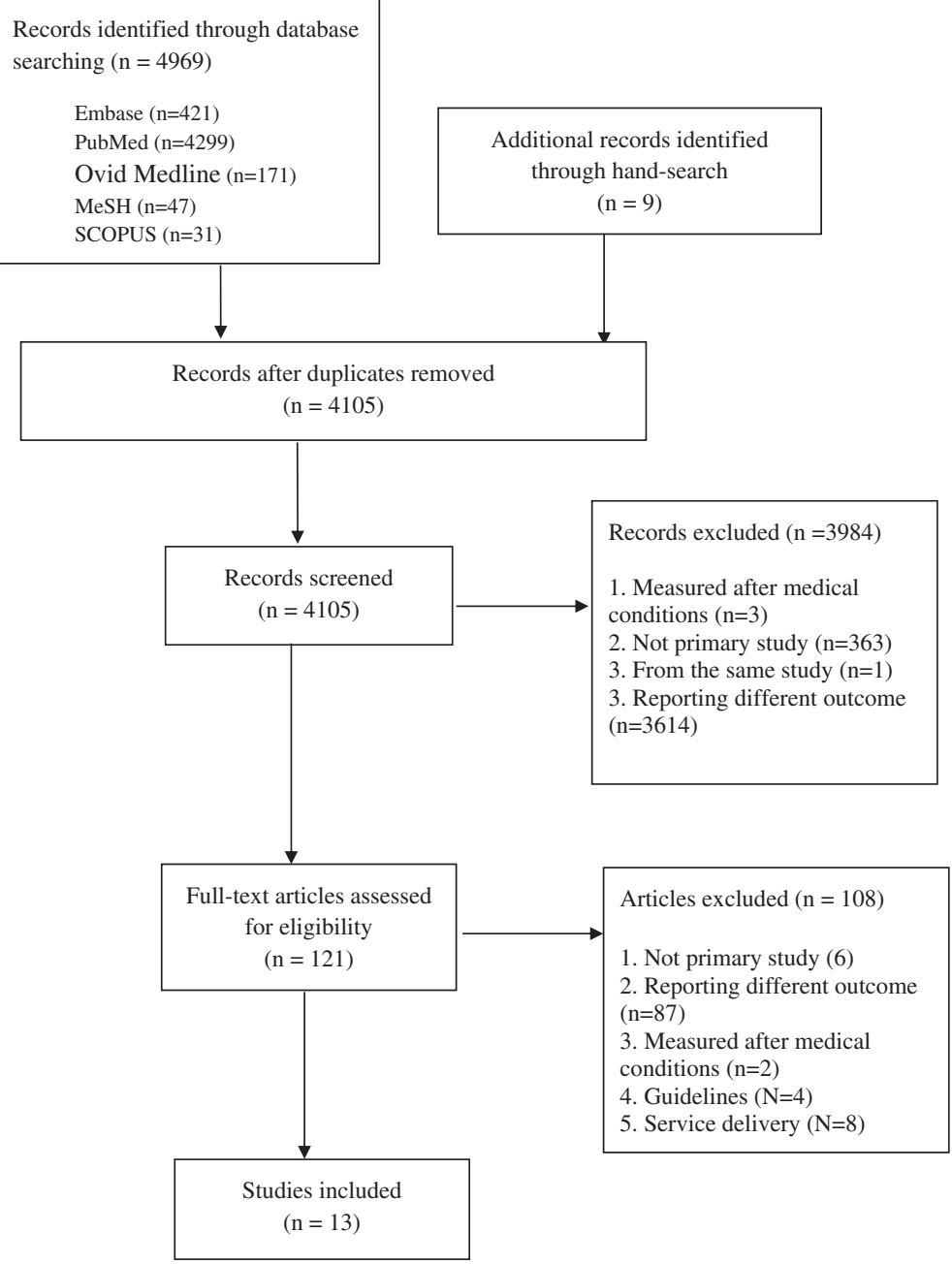

Fig. 1 PRISMA flow diagram of selection process 
for eligibility. The reviewers had no difference regarding to the selection of eligible publications. Studies were eligible if: (1) reported on prevalence or incidence of HF in Australia; (2) not clinical trials or therapeutic studies; (3) and conducted on patients with pre-existing medical conditions such as hypertension and coronary heart disease.

\section{Data extraction and summarisation}

A summary table was prepared to ensure that all relevant data including type of study, sample size, sampling methods, age and sex of the participants, year of study, scope of the study (national or single center), method of diagnosis, and the primary outcomes (incidence and prevalence rates) were extracted. Tables 1 and 2 provides a summary of the studies included in the review. Due to heterogeneity in data sources and design of the individual studies, data were summarised narratively.

\section{Quality assessment}

Quality of the studies selected for the review were assessed using a checklist comprising the items recommended by Sanderson et al. [13]. The items in the checklist include: appropriate source population; measurement methods; methods outlined to deal with any design-specific issues such as recall bias, interviewer bias, biased loss to follow or blinding; design and/or analytical methods; and appropriate use of statistics for primary analysis of effect. Each criterion was given a score of zero or one, which was then summed in to summary score (0 to 5). The score for each article was an average value of the score assigned by two independent reviewers (BWS and DM Emdadul Hoque). The studies selected for the review had an overall quality score of three or more out of five. This study used publicly available data which does not require ethical approval.

\section{Results}

\section{Description of studies}

The search yielded 4978 citations. After screening the titles and abstracts and removing duplicates, 121 studies remained for the full text review. Thirteen studies which met the inclusion criteria were selected (Tables 1 and 2). Ten were cross-sectional studies [14-23], and three studies extrapolated data from other countries to the Australian population [24-26].

\section{Participants and method of diagnosis}

Six studies recruited participants from the community [14$16,19,21,22]$ three from clinical settings $[17,18,20]$ and the remainder used administrative data $[14,23,25,26]$. Five studies were conducted in adults ( $\geq 18$ years) [14-16, $22]$, two in those 60 years or over $[19,20]$, two in all age groups $[17,18]$, with participant's age not specified in the reminder [23-26]. Heart failure was defined based self-report [14-16, 22], echocardiography (and physical assessment) [19, 21], using modified World Health Organization criteria [20] while the rest used administrative data $[17,18,23,25,26]$ (Tables 1 and 2).

Table 1 Studies reporting prevalence of heart failure

\begin{tabular}{|c|c|c|c|c|c|c|c|}
\hline \multirow[b]{2}{*}{ Author } & \multirow[b]{2}{*}{ Participants } & \multirow[b]{2}{*}{ Type of study } & \multirow[b]{2}{*}{ Method of diagnosis } & \multicolumn{3}{|c|}{ Prevalence (\%) } & \multirow[b]{2}{*}{ Quality rating } \\
\hline & & & & Male & Female & $\overline{\text { Total }}$ & \\
\hline $\begin{array}{l}\text { Abhayaratna } \\
2006 \text { [19] }\end{array}$ & $\begin{array}{l}1275 \text { random sample, } \\
\text { aged } 60-86 \text { years }\end{array}$ & Cross sectional & physical examination, and Echo & 8.2 & 4.4 & 6.3 & 4 \\
\hline Knox 2008 [17] & $\begin{array}{l}9156 \text { of all ages, selected } \\
\text { from } 305 \text { GP centers }\end{array}$ & $\begin{array}{l}\text { Multi-center } \\
\text { Cross sectional }\end{array}$ & Medical record & - & - & 1.8 & 4.1 \\
\hline Harrison 2013 [18] & $\begin{array}{l}8707 \text { of all ages selected } \\
\text { from } 290 \text { GP centers }\end{array}$ & $\begin{array}{l}\text { Multi-center, } \\
\text { Cross sectional }\end{array}$ & Medical record & - & - & 1.5 & 4 \\
\hline NHS 2004/5 [14] & National survey on $\geq 18$ y & National survey & Self-report & 0.9 & 1.8 & 1.4 & 3 \\
\hline NHS 2007/8 [15] & National survey on $\geq 18$ y & National survey & Self-report & 1.0 & 1.7 & 1.3 & 3 \\
\hline NHS 2011/12 [16] & National survey on $\geq 18$ y & National survey & Self-report & 1.0 & 1.5 & 1.2 & 3 \\
\hline NATSIHS 2008 [22] & $\begin{array}{l}\text { National survey on } \\
\geq 18 \text { y aboriginals }\end{array}$ & Survey & Self-report & 1.74 & 2.88 & 1.0 & \\
\hline McGrady 2012 [21] & $\begin{array}{l}436 \text { random sample } \\
>18 \text { yrs }\end{array}$ & Cross sectional & Echo & 7 & 4 & 5.3 & 4.3 \\
\hline Clark 2004 [26] & No mentioned & Cross sectional & administrative data & - & - & 2.0 & 3.0 \\
\hline Clark 2005 [23] & No mentioned & Cross sectional & administrative data & - & - & 1.8 & 3.3 \\
\hline Clark 2007 [20] & $\begin{array}{l}23845, \geq 60 \text { yrs selected } \\
\text { from } 341 \text { general practice }\end{array}$ & Cross sectional & WHO criteria & - & - & 13.1 & 3.5 \\
\hline
\end{tabular}

CHF congestive heart failure, GP general practice, NHS national health survey, WHO World Health Organization, NATSIHS national aboriginal and torres strait islander health survey, Echo echocardiography 
Table 2 Studies reporting prevalence of heart failure by geographic locations

\begin{tabular}{llll}
\hline Author & Sample size & Geographic stratum (\%) & Quality rating \\
\hline Clark 2004 [26] & Not mentioned & Central and west Australia (28.8-79.9 per 1000) & 3.2 \\
& & Queensland, New South Wales, Western Australia (20.3-28.7 per 1000) & 3.3 \\
Clark 2005 [23] & Not mentioned & Australian Capital Territory (14 per 1000) \\
& & Northern Territory (29.5 per 1000) \\
McGrady 2012 & 436 random sample >18 yrs & Urban (6 \%) Remote (4 \%) \\
Clark 2007 [20] $23845, \geq 60$ yrs selected from 341 GP center & Capital cities and metropolitan (12.4\%) \\
& & Large and small rural towns (16.1\%) \\
& & Other rural and remote areas (13.9\%) \\
\hline
\end{tabular}

\section{Incidence of heart failure}

There were no studies reporting the incidence of HF in Australia. According to the AHIW (based up on extrapolation of incidence rates from large scale international cohorts to the Australian population characteristics) an estimated 30,000 new cases of HF are diagnosed each year in Australia [24], which translates in to a crude incidence rate of 2.1 per 1000 population.

\section{Prevalence of heart failure}

Prevalence of HF was reported in twelve studies $[14-23,25,26]$. Based on self-report, the prevalence of $\mathrm{HF}$ and oedema in adults was estimated to be $1.4 \%$ in the $2004 / 5,1.3 \%$ in the $2007 / 8$, and $1.2 \%$ in the 2011/12 National Health Surveyes [14-16].

The national population prevalence of HF was reported in four studies, ranging from 1.5-2.0\% [17, 18, 20, 26]. Two studies reported the prevalence of chronic conditions among a sample of 9156 [17] and 8707 [18] general practice patients adjusted for the Australian population. In these studies the prevalence of HF in the population was estimated to be $1.8 \%$ [17] and $1.5 \%$ [18], respectively. In the third study, HF data were derived by applying international HF prevalence data to the Australian population [25]. The study reported a national prevalence of 17.9 per 1000 [25]. Slightly higher prevalence rate $(2.0 \%)$ was also reported in a similar study, which extrapolated HF data from Scotland and United Kingdom to the Australian popaultion [26].

In the Canberra Heart Study, which screened 1275 people aged 60-86 years old, $6.7 \%$ (95 \% CI: $4.4 \%$ $7.1 \%$ ) of them had HF and $0.6 \%$ (95 \% CI: $0.3 \%-1.2 \%$ ) of these were previously undiagnosed [19]. In the same study, the prevalence of HF ranged between $3.1 \%$ in those 60-64 years old to $13.6 \%$ in those $80-86$ years old [19]. In another study on a sample of 23845 general practice patients aged 60 years and over, HF was reported in $13.1 \%$ of them comprising previously diagnosed cases (prevalence, $11.2 \%$ ) and newly diagnosed cases (prevalence, $1.9 \%$ ) [20] However, this rate was not adjusted for the general population.

In a study that screened 436 indigenous adults (18 years or over), HF was diagnosed in $5.3 \%$ of them, of which $65 \%$ were previously undiagnosed [21]. In the 2004/5 National Aboriginal and Torres Strait Islander Health Survey (NATSIHS) [22] the prevalence of HF among Indigenous Australians was $1.0 \%$. However, following age-standardization the prevalence of $\mathrm{HF}$ was 1.7 times higher among Indigenous than nonIndigenous Australians [22].

\section{Heart failure by gender}

In the NHS [14-16, 22] HF was almost twice common in women than in men. Prevalence rates were $0.89 \%$ vs $1.8 \%$ in the $2004 / 5$ NHS, $1.0 \%$ vs $1.7 \%$ in the NHS $2007 / 8$ and $1.0 \%$ vs $1.5 \%$ in the NHS $2011 / 12$ in men and women, respectively [14-16]. Similarly, in the 2004/ 5 NATSIHS, the age-standardized prevalence of HF was 17.4 per 1000 in men and 28.8 per 1000 in women [22]. On the other hand, In the Canberra Heart Study, HF was twice as common in men (8.2\%) than in women $(4.4 \%)$ [19]. Similarly, the prevalence of HF was $7.0 \%$ in male and $4.0 \%$ in female adult Indigenous Australians [21].

\section{Heart failure by geographic location}

Four studies reported on HF by geographic location [20, 21, 23, 25]. Clark and colleagues reported a higher prevalence of $\mathrm{HF}$ in large and small rural towns (16.1\%) than in the capital city and metropolitan areas (12.4\%) [20]. In the second study, prevalence rates ranged between $2.9 \%$ and $7.8 \%$ in Central and Western Australia and between $2.0 \%$ and $2.9 \%$ in parts of Queensland, New South Wales, and Western Australia [23]. The prevalence of $\mathrm{HF}$ also varied from 14 per 1000 in the Australian Capital Territory compared to 29 per 1000 in rural Northern Territory [25]. McGrady and colleagues also reported higher in prevalence of HF in urban Aboriginals (6.0 \%) than those in remote communities $(4.0 \%)$ [21]. 


\section{Discussion}

Our findings indicate that the prevalence of HF in the Australian population ranges from 1.0-2.0\%, and varies by Indigenous status, gender, age, and geographic location. The burden of HF was higher among Indigenous than non-Indigenous Australians, and in rural and remote than in capital city and metropolitan areas. In most of the studies reviewed, HF was more prevalent in women than in men.

As indicated in the AIHW reports, there are no studies reporting on the incidence of HF. [7] The only data available was the number of new cases of HF diagnosed each year, estimated based on overseas data, which may not be generalizable to the population due to limitations inherent to the process of extrapolation [24].

Our findings of the prevalence of $\mathrm{HF}$ in Australia (1.0-2.0\%) is congruent with data from Europe and North America where prevalence of HF range between $1.3 \%$ and $2.2 \%$ [1, 27-29]. Consistent with existing knowledge [30, 31] HF was three or more times higher in the elderly than in the population. In general, the NHS [14-16] reported a lower prevalence of HF compared with the individual studies $[17,18,20,26]$ which may be related to the use of self-reported diagnosis in the NHS [7]. The significant proportion of previously undiagnosed HF patients $[19,21]$ also reveal a chance of underestimation when HF is defined based on selfreported diagnosis.

In most of the studies [14-16, 22] HF was twice more prevalent in women than men, although men were more affected than women in two other studies [19, 21]. The inconsistency in the prevalence of HF by gender has been reported in several studies [3, 32, 33]. In Australia, major risk factors of HF including coronary heart diseases, diabetes, and high blood pressure are higher in men than in women $[7,34]$. However, risk factors of HF such as diabetes, hypertension, and left ventricular dysfunction have stronger risk of progression to $\mathrm{HF}$ in women than men, which may explain the higher prevalence of HF among women [30, 35]. The higher burden of HF among women could be also be attributed to the longer life expectancy and higher incidence of $\mathrm{HF}$ in later years of life in women than men [36].

The higher prevalence of $\mathrm{HF}$ among Indigenous Australians is consistent with the existing literature. The latest Australian statistics shows that cardiovascular diseases are 1.3 times more common among Indigenous than their non-Indigenous counterparts [8]. The excess burden of HF, cardiovascular diseases in general, in Indigenous population is related to the overall disparity in the social and economic status that impact on their health status [22]. The risk factors of HF are also reported to be more prevalent among Indigenous population than the nationally reported data [21].
According to previous studies [22, 25] the disproportionately higher burden of HF in rural and remote towns is related to the concentration of older age inhabitants and higher prevalence of socio-demographic risk factors in these regions. Indigenous Australians, who have higher prevalence of HF also concentrate in rural and remote towns [25]. The comparatively lower access to healthcare services in rural and remote regions, which may affect early identification and management of the risk factors predisposing to $\mathrm{HF}$, could also contribute to the geographic disparity [20, 23, 25].

The syndrome of HF has different causes and diverse clinical presentations, and long-term clinical evolution that makes its diagnosis challenging [1, 37]. Studies based on self-reported diagnosis are likely to underestimate the burden of HF because participants may not know their HF status [37, 38]. Limitations inherent to use of administrative data such misclassification may also compromise the validity of HF data from such studies. Therefore the overall estimate of the burden of HF is likely to be affected by the use of different definitions and measurement methods for HF.

This systematic review has some limitations. There were limited studies on epidemiology of $\mathrm{HF}$ in Australia and therefore studies that used varying $\mathrm{HF}$ definition (such as heart failure and oedema) were included in the review. Due to the limited number of studies, further description of the pattern of HF over time was not possible. Moreover, the search was restricted to PubMed indexed journals, and unpublished reports. As a result, articles published non-PubMed indexed journals may have been missed. Despite these limitations, the current review still provides valuable information on the prevalence of HF in the Australian population. Extensive and systematic literature search using pre-defined quality assessment and inclusion criteria were employed.

\section{Conclusions}

This review shows that the prevalence heart failure in Australia is similar to other developed countries, however it has a significant burden in specific demographic profiles in the country, namely Indigenous groups, females and those who reside in rural and remote areas. Further population-level studies, with clearly defined method of diagnosis, are needed for a more accurate description of the burden of HF in Australia.

\section{Additional files}

Additional file 1: PRISMA guideline for reporting systematic reviews. (DOCX $17 \mathrm{~kb}$ )

Additional file 2: Literature search history: a sample using Ovid MEDLINE. (DOC 63 kb) 


\section{Competing interests}

The authors declare that they have no competing interests.

\section{Authors' contribution}

BWS, AJO, MPM, HK, and CMR contributed to the conception of the study, participated in writing the manuscript. BWS: performed the literature search. BWS and MMP: screened publications and selected eligible studies. All authors read and approved the final manuscript.

\section{Acknowledgements}

We are grateful to DM Emdadul Hoque Department of Epidemiology and Preventive Medicine, Monash University, for his assistance in assessing the quality of the publications included in the review. This work was supported by a NHMRC Program Grant (1092642) awarded to HK and CMR. CMR is supported by a Research Fellowship from the National Health and Medical Research Council of Australia (NHMRC). The funding bodies had no role in the design and conduct of the study, the collection, management, analysis and interpretation of the data, or the preparation, review, or approval of the manuscript.

\section{Author details}

'Centre of Cardiovascular Research and Education in Therapeutics, Department of Epidemiology and Preventive Medicine, Monash University, 99 Commercial Road, Melbourne, Vic 3004, Australia. ${ }^{2}$ School of Public Health, Mekelle University, Mekelle, Ethiopia. ${ }^{3}$ School of Public Health, Department of Epidemiology and Preventive Medicine, Monash University, Melbourne, Australia. ${ }^{4}$ School of Public Health, Curtin University, Perth, Australia.

Received: 4 November 2015 Accepted: 29 January 2016

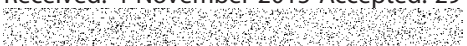

\section{References}

1. Ponikowski P, Anker SD, AlHabib KF, Cowie MR, Force TL, Hu S, et al. Heart failure: preventing disease and death worldwide. ESC Heart Failure. 2014;1:425.

2. McMurray JJV, Stewart S. The burden of heart failure. Eur Heart J Supplements. 2002;4:D50-8.

3. Bleumink GS, Knetsch AM, Sturkenboom MC, Straus SM, Hofman A, Deckers JW, et al. Quantifying the heart failure epidemic: prevalence, incidence rate, lifetime risk and prognosis of heart failure. The Rotterdam Study. Eur Heart J. 2004;25: 1614-9.

4. Hobbs FD, Roalfe AK, Davis RC, Davies MK, Hare R. Midlands Research Practices Consortium (MidReC). Prognosis of all-cause heart failure and borderline left ventricular systolic dysfunction: 5 year mortality follow-up of the Echocardiographic Heart of England Screening Study (ECHOES). Eur Heart J. 2007;28:1128-34.

5. Willcox S. Chronic diseases in Australia: the case for changing course. Background and policy paper No. 02/2014. Melbourne, Mitchell Institute. Available at: http://www.mitchellinstitute.org.au/reports/chronic-diseases-inaustralia-the-case-for-changing-course/ [Cited 28 September 2015].

6. Reid CM. Cardiovascular diseases in Australia: calm before a new storm? Clin Exp Pharmacol Physiol. 2013;40(6):345-6.

7. Australian Institute of Health and Welfare. Cardiovascular disease, diabetes and chronic kidney disease- Australian facts: Prevalence and incidence. In: Cardiovascular, diabetes and chronic kidney disease series no. 2. Cat. no. CDK 2 Canberra: AlHW: 2014

8. Waters A-M, Trinh L, Chau T, Bourchier M, Moon L. Latest statistics on cardiovascular disease in Australia. Clin Exp Pharmacol Physiol. 2013:40:347-56.

9. Woods JA, Katzenellenbogen JM, Davidson PM, Thompson SC. Heart failure among indigenous Australians: a systematic review. BMC Cardiovasc Disord. 2012;12:99.

10. Snyder ML, Love SA, Sorlie PD, Rosamond WD, Antini C, Metcalf PA, et al. Redistribution of heart failure as the cause of death: the Atherosclerosis Risk in Communities Study. Popul Health Metr. 2014;12:10.

11. Inglis SC, Clark RA, Shakib S, Wong DT, Molaee P, Wilkinson D, et al. Hot summers and heart failure: seasonal variations in morbidity and mortality in Australian heart failure patients (1994-2005). Eur J Heart Fail. 2008;10:540-9.

12. Moher D, Liberati A, Tetzlaff J, Altman D, The PRISMA Group. Preferred Reporting Items for Systematic Reviews and Meta-Analyses: the PRISMA statement. PLoS Med. 2009;6(6):e1000097.
13. Sanderson S, Tatt ID, Higgins JP. Tools for assessing quality and susceptibility to bias in observational studies in epidemiology: a systematic review and annotated bibliography. Int J Epidemiol. 2007;36:666-76.

14. Australian Bureau of Statistics, National Health Survey: Summary of results 2004-05. Cat. no. 4364.0.Canberra:ABS;2006.

15. Australian Bureau of Statistics, National Health Survey: Summary of Results, 2007-2008 (Reissue). Cat. no. 43640D0020_20072008. Canberra: ABS;2009.

16. Australian Bureau of Statistics, National Health Survey: First Results, 2011-12. Cat. no. 43640D0003 20112012. Canberra: ABS; 2012

17. Knox SA, Harrison CM, Britt HC, Henderson J. Estimating prevalence of common chronic morbidities in Australia. Med J Aust. 2008;189:66-70.

18. Harrison C, Britt H, Miller G, Henderson J. Prevalence of chronic conditions in Australia. PloS One. 2013:8:e67494.

19. Abhayaratna WP, Smith WT, Becker NG, Marwick TH, Jeffery IM, McGill DA. Prevalence of heart failure and systolic ventricular dysfunction in older Australians: the Canberra Heart Study. Med J Aust. 2006;184:151-4.

20. Clark RA, Eckert KA, Stewart S, Phillips SM, Yallop JJ, Tonkin AM, et al. Rural and urban differentials in primary care management of chronic heart failure: new data from the CASE study. Med J Aust. 2007;186:441-5.

21. McGrady M, Krum H, Carrington MJ, Stewart S, Zeitz C, Lee GA, et al. Heart failure, ventricular dysfunction and risk factor prevalence in Australian aboriginal peoples: the Heart of the Heart Study. Heart. 2012:98(21):1562-7.

22. AlHW, Penm E. Cardiovascular disease and its associated risk factors in Aboriginal and Torres Strait Islander peoples 2004-05. In: Cardiovascular disease series no. 29. Cat. no. CVD 41. Canberra: Australian Institute of Health and Welfare; 2008.

23. Clark RA, Driscoll A, Nottage J, McLenan S, Coombie DM, Bamford EJ, et al. Inequitable provision of optimal services for patients with chronic heart failure: a national geo-mapping study. Med J Aust. 2007;186:169e73.

24. AlHW: Field B. Heart failure... what of the future? Bulletin no. 6. AlHW Cat. No. AUS 34. Canberra: AlHW; 2003

25. Clark RA, McLennan S, Eckert K, Dawson A, Wilkinson D, Stewart S. Chronic heart failure beyond city limits. Rural Remote Health. 2005:5:443.

26. Clark RA, McLennan S, Dawson A, Wilkinson D, Stewart S. Uncovering a hidden epidemic: a study of the current burden of heart failure in Australia. Heart Lung Circ. 2004;13:266-73.

27. Quach S, Blais C, Quan H. Administrative data have high variation in validity for recording heart failure. Can J Cardiol. 2010;26(8):306-12.

28. Zarrinkoub R, Wettermark $B$, Wändell $P$, Mejhert $M$, Szulkin $R$, Ljunggren $G$, et al. The epidemiology of heart failure, based on data for 2.1 million inhabitants in Sweden. Eur J Heart Fail. 2013;15(9):995-1002.

29. Valle R, Baccichetto R, Barro S, Calderan A, Carbonieri E, Chinellato M, et al. Heart failure in Eastern Veneto: prevalence, hospitalization rate, adherence to guidelines and social costs. Monaldi Arch Chest Dis. 2006:66(1):63-74

30. Bui AL, Horwich TB, Fonarow GC. Epidemiology and risk profile of heart failure. Nat Rev Cardiol. 2011:8:30-41.

31. Bhatnagar P, Williams J, Townsend N. The epidemiology of cardiovascular disease in the United Kingdom 2014. Heart 2015 doi:10.1136/heartinl- 2015-307516

32. Mehta PA, Cowie MR. Gender and heart failure: a population perspective. Heart. 2006:92 suppl 3:iii14-8.

33. Patten RD. Models of gender differences in cardiovascular disease. Drug Discov Today Dis Models. 2007:4(4):227-32

34. Nichols M, Peterson K, Herbert J, Allender S. Australian heart disease statistics. Overweight, obesity and cardiovascular disease - past, present and future. Melbourne: National Heart Foundation of Australia;2015.

35. Meredith PA, Ostergren J. From hypertension to heart failure - are there better primary prevention strategies? J Renin Angiotensin Aldosterone Syst. 2006;7:64-73

36. Lenzen MJ, Rosengren A, OP Reimer WJMS, Follath F, Boersma E, Simoons ML et al. Management of patients with heart failure in clinical practice: differences between men and women. Heart. 2008:94:e10.

37. Adams Jr KF, Zannad F, France N. Clinical definition and epidemiology of advanced heart failure. Am Heart J. 1998;135:S-204-15.

38. Krum H, Abraham WT. Heart failure Lancet 2009:373:941-55. 